\title{
Medical Treatment of a Staghorn Calculus: The Ultimate Noninvasive Therapy
}

\author{
Joshua D. Chamberlin, MD, and Ralph V. Clayman, MD
}

\section{Abstract}

A 77-year-old female presented with bilateral staghorn calculi. She underwent an uneventful left percutaneous nephrolithotomy (PCNL); the stone analysis revealed a 90\% struvite and $10 \%$ calcium phosphate stone. Treatment of the right stone was postponed by the patient. During the next 9 months, her family physician gave her multiple courses of culture-directed antibiotics due to breakthrough urinary-tract infections, despite her also being on a prophylactic antibiotic. After 9 months, she agreed to undergo her right PCNL. Preoperatively, a non-contrast CT scan was obtained; it revealed complete resolution of the right staghorn calculi.

\section{Clinical History}

A 77-YEAR-OLD FEMALE was referred due to a history of intermittent left flank pain and recurrent urinary-tract infections. Laboratory studies by her physician revealed worsening renal function; subsequently, a CT scan showed bilateral $>3-\mathrm{cm}$ renal staghorn calculi involving three renal calyces bilaterally with moderate left hydronephrosis. Hounsfield units on the left stone were 694 and on the right stone were 664. Significant in her medical history was a parathyroidectomy 7 years ago for hyperparathyroidism, discovered following metabolic workup for nephrolithiasis; serum parathyroid hormone and calcium levels returned to normal. Her medical history included hypertension, chronic kidney disease, arthritis, atrial fibrillation, hepatitis B, hyperlipidemia, and anemia. Her prior surgeries included bilateral hip and knee prostheses and oophorectomy. Her medications included prophylactic dose cephalexin, lisinopril, furosemide, valsartan, calcium carbonate, acetaminophen with codeine, colace, amiodarone, warfarin, lovastatin, and iron. Her family history revealed kidney stones in her daughter.

She underwent an MAG-3 renal Lasix scan, which showed split function of $49.3 \%$ on the left and $50.7 \%$ on the right, with decreased drainage on the left side ( $\mathrm{T} 1 / 2$ of 22.17 minutes on the left vs 5.33 minutes on the right) with associated left hydronephrosis. After a 7-day course of levofloxacin, she underwent an upper pole left percutaneous nephrolithotomy (PCNL) with bridging anticoagulation therapy. A low dose

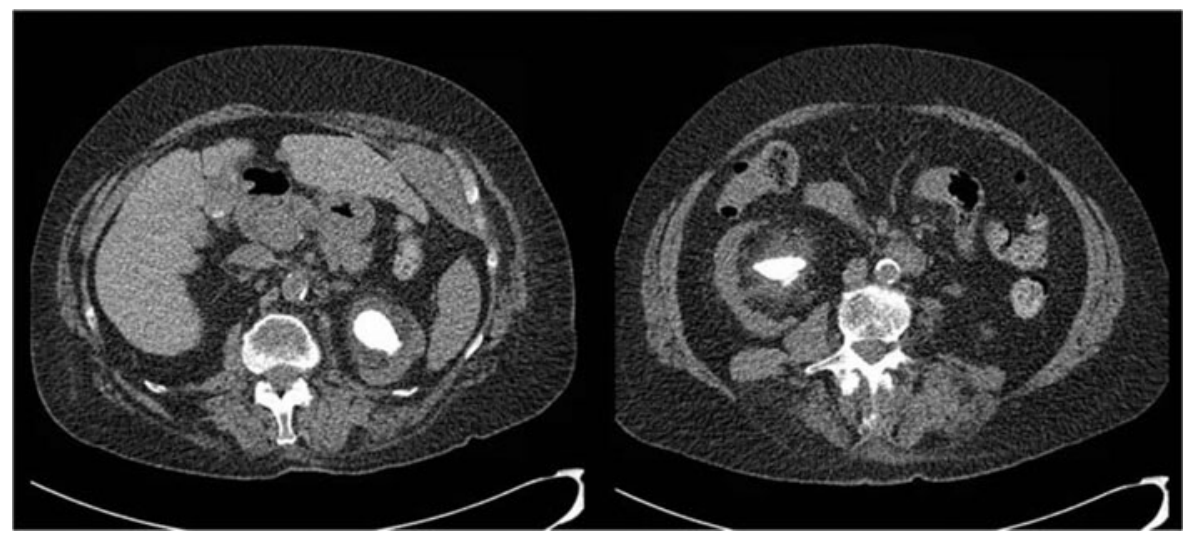

FIG. 1. CT scan prior to left PCNL: Bilateral staghorn stones, left $3.2 \mathrm{~cm}$ renal staghorn involving 3 calyces, HU of 694 , and right $3.4 \mathrm{~cm}$ renal staghorn involving 3 calyces, HU of 664 . There is mild left hydronephrosis, bilateral parenchymal thinning and two left renal parenchymal calcifications (not shown).

Department of Urology, University of California, Irvine, Orange, California.

(C) Chamberlin and Clayman 2015; Published by Mary Ann Liebert, Inc. This Open Access article is distributed under the terms of the Creative Commons License (http://creativecommons.org/licenses/by/4.0), which permits unrestricted use, distribution, and reproduction in any medium, provided the original work is properly credited. 
FIG. 2. CT scan after 9 months of antibiotic therapy: No new left renal stones, improvement of left hydronephrosis and complete resolution of right renal stone.

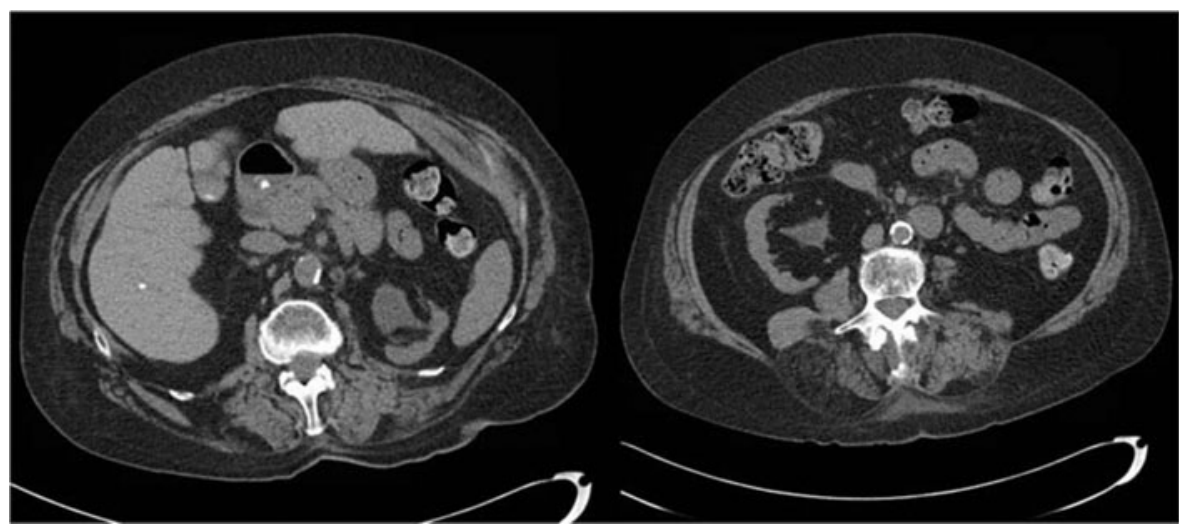

CT scan of the abdomen and pelvis without contrast the following morning revealed resolution of the left collecting system staghorn with persistence of a $4 \mathrm{~mm}$ and $8 \mathrm{~mm}$ upper and lower pole renal parenchymal calcification, respectively; the right staghorn calculus was unchanged. Stone analysis demonstrated $90 \%$ struvite and $10 \%$ calcium phosphate, with stone culture positive for Enterococcus faecalis and Proteus mirabilis. She was discharged from the hospital on postoperative day 3. She was scheduled to undergo right PCNL 6 weeks later, but postponed her surgery due to her husband's poor health and ultimate passing. As such, her surgery was delayed for 9 months.

\section{Physical Examination}

Examination revealed an elderly Caucasian female who was 5.0 feet tall with body mass index of $32.5 \mathrm{~kg} / \mathrm{m}^{2}$. Her blood pressure was 167/67 with normal remaining vital signs. She had a 2/6 systolic ejection murmur. Abdomen was soft with a well-healed midline abdominal incision. There was no costovertebral tenderness bilaterally. PCNL tract on the left showed a well-healed scar. There was $1+$ peripheral edema. The remainder of the examination was unremarkable.
Diagnostic studies urinalysis: Specific gravity $1.012, \mathrm{pH}$ 7.5 , protein 100 , nitrite positive, leukocyte esterase positive, red blood cell count $>182$, white blood cell count 176 . Urine culture: $>100,000 \mathrm{CFU}$ of E. faecalis and 11,000 CFU of $P$. mirabilis.

Laboratory studies: White blood cells count 7.1, hemoglobin 12.7 , hematocrit 37.2 , platelets 206 . International normalized ratio 2.5 , sodium 140 , potassium 4.4 , chloride 104 , carbon dioxide 23 , blood urea nitrate 53 , creatinine 2.2 , glomerular filtration rate 31 , glucose 85 , calcium 8.8 , magnesium 1.8, phosphorous 3.2.

Initial CT scan prior to left PCNL (Fig. 1): A left $3.2 \mathrm{~cm}$ renal staghorn involving three calyces with HU of 694 and a right $3.4 \mathrm{~cm}$ renal staghorn involving three calyces with $\mathrm{HU}$ of 664 . There are two separate left renal parenchymal calcifications, $4 \mathrm{~mm}$ and $8 \mathrm{~mm}$, left mild hydronephrosis, and bilateral parenchymal thinning.

CT scan 1 day following left PCNL: Complete resolution of left staghorn stone with persistence of $4 \mathrm{~mm}$ and $8 \mathrm{~mm}$ left renal parenchymal calcifications and persistence of a $3.4-\mathrm{cm}$ right renal staghorn.

CT scan 9 months later, prior to scheduled right PCNL (Fig. 2): Unchanged left renal parenchymal calcifications, no

Table 1. Urine Cultures

\begin{tabular}{|c|c|c|c|c|}
\hline Urine source & Bacteria & $\begin{array}{l}\text { Amount } \\
(C F U)\end{array}$ & Susceptible & Resistant \\
\hline \multirow{2}{*}{$\begin{array}{l}\text { Clean } \\
\text { midstream }\end{array}$} & Enterococcus faecalis & $>100,000$ & Nitrofurantoin, ampicillin & Ciprofloxacin \\
\hline & Proteus mirabilis & 11,000 & SMX-TMP, ciprofloxacin, cephalexin & Nitrofurantoin \\
\hline Cystoscopy & E. faecalis & $>100,000$ & Nitrofurantoin, ampicillin & Ciprofloxacin \\
\hline \multirow{2}{*}{$\begin{array}{l}\text { Left renal } \\
\text { stone }\end{array}$} & E. faecalis & $2+$ & Nitrofurantoin, ampicillin & Ciprofloxacin \\
\hline & P. mirabilis & Few & SMX-TMP, ciprofloxacin, cephalexin & Nitrofurantoin \\
\hline \multirow{2}{*}{$\begin{array}{l}\text { Clean } \\
\text { midstream }\end{array}$} & E. faecalis & $>100,000$ & Nitrofurantoin, ampicillin & Ciprofloxacin \\
\hline & Escherichia coli & 4000 & Nitrofurantoin, SMX-TMP, cephalexin & Ciprofloxacin \\
\hline \multirow{3}{*}{$\begin{array}{l}\text { Clean } \\
\text { midstream }\end{array}$} & E. faecalis & $>100,000$ & Nitrofurantoin, ampicillin & Ciprofloxacin \\
\hline & Klebsiella pneumonia & 1000 & $\begin{array}{l}\text { Nitrofurantoin, SMX-TMP, } \\
\text { cephalexin, ciprofloxacin }\end{array}$ & \\
\hline & E. coli & 1000 & $\begin{array}{l}\text { Nitrofurantoin, SMX-TMP, } \\
\text { cephalexin, ciprofloxacin }\end{array}$ & \\
\hline \multirow{2}{*}{$\begin{array}{l}\text { Clean } \\
\text { midstream }\end{array}$} & E. faecalis & $>100,000$ & Nitrofurantoin, ampicillin & Ciprofloxacin \\
\hline & E. coli & 1000 & Nitrofurantoin, ciprofloxacin & $\begin{array}{l}\text { SMX-TMP, } \\
\text { cephalexin }\end{array}$ \\
\hline
\end{tabular}

SMX-TMP, sulfamethoxazole-trimethoprim. 
TABle 2. Antibiotics

\begin{tabular}{|c|c|c|c|}
\hline & Dose & Duration & $\begin{array}{c}\text { No. of } \\
\text { treatments }\end{array}$ \\
\hline \multicolumn{4}{|c|}{ Prophylactic antibiotics } \\
\hline Cephalexin & $250 \mathrm{mg}$ daily & 5 months & \\
\hline Nitrofurantoin & $100 \mathrm{mg}$ daily & 1 month & \\
\hline \multicolumn{4}{|c|}{ Therapeutic antibiotics } \\
\hline Nitrofurantoin & $\begin{array}{l}\text { 50-100 mg } \\
\text { BID }\end{array}$ & $7-14$ days & 6 \\
\hline Ciprofloxacin & $500 \mathrm{mg}$ BID & 7 days & 3 \\
\hline Levofloxacin & $250 \mathrm{mg}$ daily & 7 days & 2 \\
\hline SMX-TMP & $\begin{array}{l}800 \mathrm{mg} / 160 \mathrm{mg} \\
\text { BID }\end{array}$ & 7 days & 4 \\
\hline Amoxicillin & $500 \mathrm{mg}$ BID & 7 days & 2 \\
\hline
\end{tabular}

new left renal stones, improvement of left hydronephrosis and complete resolution of right renal stone.

\section{Intervention}

She was scheduled to undergo PCNL on the right, but the patient delayed surgery due to her husband's ill health and subsequent death. During this time, she was placed on a 5 -month course of prophylactic antibiotics cephalexin $250 \mathrm{mg}$ PO daily and a 1-month prophylactic course of nitrofurantoin $100 \mathrm{mg}$ PO daily, but continued to have symptomatic urinarytract infections that were positive for E. faecalis, $P$. mirabilis, Escherichia coli, and Klebsiella pneumonia (Table 1). As such, over the next 9 months, she underwent 17 culturedirected therapeutic courses of antibiotics prescribed by her family physician, often with two antibiotics given concomitantly. The antibiotics included nitrofurantoin, ciprofloxacin, levofloxacin, sulfamethoxazole-trimethoprim (SMX-TMP), and amoxicillin (Table 2).

\section{Outcome}

The patient was rendered stone free of renal collecting system stones on the left following the left PCNL, with only a $4 \mathrm{~mm}$ and an $8 \mathrm{~mm}$ calcification persisting in the renal parenchyma. The patient was found to have complete dissolution of the right renal stone after 9 months of myriad antibiotic therapies.

According to the 2005 AUA guidelines on the management of staghorn calculi, standard of care includes definitive treatment of newly diagnosed otherwise healthy patients with staghorn calculi to render them stone free with intervening procedures. ${ }^{1}$ Several studies have shown that nonsurgical management of staghorn calculi with antibiotics, urease inhibitors or supportive measures lead to renal deterioration, recurrent urinary-tract infections, sepsis, pain, and increased mortality. $^{2}$

While antibiotics alone have been shown to be insufficient in the definitive management of struvite stones, they play a clear role for the safe management of planned directed therapy. Both the EUA and AUA recommend antibiotic therapy in the presence of a suspected struvite stones with associated infection; however, while antibiotics are typically given for 1 to 2 weeks prior to the planned surgical procedure, high-level guidelines for specific antibiotic choice, timing, and duration have not been established. ${ }^{1,3}$ The curious finding of this case is that long-term very aggressive antibiotic therapy in and of itself resulted in complete resolution of a $3-\mathrm{cm}$ presumably struvite stone. This observation may warrant further investigation as to the potential pharmaceutical dissolution of struvite calculi and may warrant obtaining a CT scan prior to PCNL in cases of suspected struvite stone in patients who have had a prolonged course of antibiotic therapy prior to their planned date of surgery.

\section{Disclosure Statement}

No competing financial interests exist.

\section{References}

1. Preminger GM, Assimos DG, Lingeman JE, et al. Chapter 1: AUA guidelines on management of staghorn calculi: Diagnosis and treatment recommendations. J Urol 2005;173: 1991-2000.

2. Flannigan R, Choy WH, Chew B, et al. Renal struvite stones-Pathogenesis, microbiology, and management strategies. Nat Rev Urol 2014;11:333-341.

3. Türk C, Petř́ík A, Sarica $\mathrm{K}$ et al. EAU Guidelines on Diagnosis and Conservative Management of Urolithiasis. Eur Urol 2015; [Epub ahead of print]; DOI: 10.1016/ j.eururo.2015.07.040.

\section{Address correspondence to: Ralph V. Clayman, MD University of California, Irvine Department of Urology 333 City Blvd. West, Suite 2100 Orange, CA 92868 \\ E-mail: rclayman@uci.edu}

$\begin{aligned} & \text { Abbreviations Used } \\ \mathrm{CT} & =\text { computed tomography } \\ \mathrm{HU} & =\text { Hounsfield units } \\ \mathrm{PCNL} & =\text { percutaneous nephrolithotomy } \\ \text { SMX-TMP } & =\text { sulfamethoxazole-trimethoprim }\end{aligned}$

Cite this article as: Chamberlin JD and Clayman RV (2015) Medical treatment of a staghorn calculus: the ultimate noninvasive therapy, Journal of Endourology Case Reports 1:1, 21-23, DOI: 10.1089/cren.2015.29003.jdc. 